\title{
Two-Year Outcomes after Transcatheter or Surgical Aortic-Valve Replacement
}

\author{
Susheel K. Kodali, M.D., Mathew R. Williams, M.D., Craig R. Smith, M.D., \\ Lars G. Svensson, M.D., Ph.D., John G. Webb, M.D., Raj R. Makkar, M.D., \\ Gregory P. Fontana, M.D., Todd M. Dewey, M.D., Vinod H. Thourani, M.D., \\ Augusto D. Pichard, M.D., Michael Fischbein, M.D., Ph.D., Wilson Y. Szeto, M.D., \\ Scott Lim, M.D., Kevin L. Greason, M.D., Paul S. Teirstein, M.D., \\ S. Chris Malaisrie, M.D., Pamela S. Douglas, M.D., Rebecca T. Hahn, M.D., \\ Brian Whisenant, M.D., Alan Zajarias, M.D., Duolao Wang, Ph.D., \\ Jodi J. Akin, M.S., William N. Anderson, Ph.D., and Martin B. Leon, M.D., \\ for the PARTNER Trial Investigators*
}

\section{ABSTRACT}

From Columbia University Medical Center and New York Presbyterian Hospital (S.K.K., M.R.W., C.R.S., R.T.H., M.B.L.) and Lenox Hill Hospital (G.P.F.) - both in New York; Cleveland Clinic Foundation, Cleveland (L.G.S.); University of British Columbia and St. Paul's Hospital, Vancouver, Canada (J.G.W.); Cedars-Sinai Medical Center, Los Angeles (R.R.M.); Medical City Dallas, Dallas (T.M.D.); Emory University School of Medicine, Atlanta (V.H.T.); Washington Hospital Center, Washington, DC (A.D.P.); Stanford University Medical School, Palo Alto (M.F.), Scripps Clinic, La Jolla (P.S.T.), and Edwards Lifesciences, Irvine (J.J.A., W.N.A.) - all in California; Hospital of the University of Pennsylvania, Philadelphia (W.Y.S.); University of Virginia, Charlottesville (S.L.); Mayo Clinic, Rochester, MN (K.L.G.); Northwestern University, Chicago (S.C.M.); Duke University Medical Center, Durham, NC (P.S.D.); Intermountain Medical Center, Salt Lake City (B.W.); Washington University Medical School and Barnes-Jewish Hospital, St. Louis (A.Z.); and London School of Hygiene and Tropical Medicine, London (D.W.). Address reprint requests to Dr. Kodali at Columbia University Medical Center/ New York Presbyterian Hospital, 161 Fort Washington Ave., 6th Fl., New York, NY 10032, or at sk2427@columbia.edu.

*The investigators, institutions, and research organizations participating in the Placement of Aortic Transcatheter Valves (PARTNER) trial are listed in the Supplementary Appendix, available at NEJM.org.

This article (10.1056/NEJMoal200384) was published on March 26, 2012, at NEJM.org.

N Engl J Med 2012;366:1686-95.

Copyright (@) 2012 Massachusetts Medical Society.

\section{BACKGROUND}

The Placement of Aortic Transcatheter Valves (PARTNER) trial showed that among high-risk patients with aortic stenosis, the 1-year survival rates are similar with transcatheter aortic-valve replacement (TAVR) and surgical replacement. However, longerterm follow-up is necessary to determine whether TAVR has prolonged benefits.

\section{METHODS}

At 25 centers, we randomly assigned 699 high-risk patients with severe aortic stenosis to undergo either surgical aortic-valve replacement or TAVR. All patients were followed for at least 2 years, with assessment of clinical outcomes and echocardiographic evaluation.

\section{RESULTS}

The rates of death from any cause were similar in the TAVR and surgery groups (hazard ratio with TAVR, 0.90; 95\% confidence interval [CI], 0.71 to $1.15 ; \mathrm{P}=0.41$ ) and at 2 years (Kaplan-Meier analysis) were 33.9\% in the TAVR group and 35.0\% in the surgery group $(\mathrm{P}=0.78)$. The frequency of all strokes during follow-up did not differ significantly between the two groups (hazard ratio, 1.22; 95\% CI, 0.67 to 2.23; $\mathrm{P}=0.52)$. At 30 days, strokes were more frequent with TAVR than with surgical replacement ( $4.6 \%$ vs. $2.4 \%, \mathrm{P}=0.12)$; subsequently, there were 8 additional strokes in the TAVR group and 12 in the surgery group. Improvement in valve areas was similar with TAVR and surgical replacement and was maintained for 2 years. Paravalvular regurgitation was more frequent after TAVR $(\mathrm{P}<0.001)$, and even mild paravalvular regurgitation was associated with increased late mortality $(\mathrm{P}<0.001)$.

\section{CONCLUSIONS}

A 2-year follow-up of patients in the PARTNER trial supports TAVR as an alternative to surgery in high-risk patients. The two treatments were similar with respect to mortality, reduction in symptoms, and improved valve hemodynamics, but paravalvular regurgitation was more frequent after TAVR and was associated with increased late mortality. (Funded by Edwards Lifesciences; ClinicalTrials.gov number, NCT00530894.) 
ORTIC STENOSIS IS ASSOCIATED WITH high mortality after the appearance of cardiac symptoms. ${ }^{1}$ Nevertheless, many patients do not undergo surgical aortic-valve replacement owing to real or perceived increased risks associated with surgery. ${ }^{2-5}$ Transcatheter aorticvalve replacement (TAVR) has emerged as an alternative therapy in high-risk patients with aortic stenosis. ${ }^{6-10}$ Observational registries from various countries have reported 1-month and 1-year outcomes after TAVR, ${ }^{11-14}$ but there are limited long-term follow-up data. ${ }^{15}$

The Placement of Aortic Transcatheter Valves (PARTNER) trial was a randomized trial comparing TAVR with standard-of-care therapies in highrisk patients with aortic stenosis. One-year mortality outcomes from PARTNER showed that TAVR was superior to standard therapy in patients who could not undergo surgery ${ }^{16}$ and was noninferior to surgical replacement in high-risk patients who could undergo surgery. ${ }^{17}$ However, longer-term data are required to assess valve durability and to monitor late clinical complications, before TAVR is used more widely in clinical practice. This report describes the 2-year (and longer) clinical outcomes and echocardiographic findings after TAVR or surgical aortic-valve replacement in the high-risk patients in the PARTNER trial who could undergo surgery.

\section{METHODS}

\section{PATIENTS}

Patient selection for this cohort of the PARTNER trial has been described previously. ${ }^{17}$ Inclusion criteria were severe symptomatic aortic stenosis (an aortic-valve area $\leq 0.8 \mathrm{~cm}^{2}$ plus a peak velocity $\geq 4 \mathrm{~m}$ per second or a mean valve gradient $\geq 40 \mathrm{~mm} \mathrm{Hg}$ ) and high-risk status for surgical aortic-valve replacement, as determined by experienced surgeons. Patients were considered to be at high surgical risk if they had coexisting conditions that were associated with a risk of death of at least $15 \%$ by 30 days after the operation.

\section{STUDY DEVICE AND PROCEDURE}

The SAPIEN heart-valve system (Edwards Lifesciences) and the TAVR procedure have been described previously. ${ }^{16,17}$ Most procedures were performed in a hybrid operating room with a fixed fluoroscopic imaging system, while the patient was under general anesthesia, and with transesophageal echocardiography. Transapical TAVR was per- formed through a small intercostal incision over the left ventricular apex with the use of a dedicated delivery catheter and the same SAPIEN valve.

Heparin was administered during the procedure, and dual antiplatelet therapy (aspirin and clopidogrel) was recommended for 6 months afterward. The outpatient regimen was frequently modified by the treating physicians because of increased bleeding risks.

\section{STUDY DESIGN AND OVERSIGHT}

The study design and data-management practices have been described previously. ${ }^{16,17}$ A total of 699 patients from 25 sites were randomly assigned to TAVR or surgical replacement. Patients assigned to TAVR were treated by either the transfemoral or transapical approach on the basis of whether peripheral arteries could accommodate the large sheaths required (22 French for the $23-\mathrm{mm}$ valve and 24 French for the $26-\mathrm{mm}$ valve). Patients who were randomly assigned to surgical replacement were stratified according to whether a transfemoral or transapical approach would have been used.

The study was designed and monitored by the sponsor, Edwards Lifesciences, and the executive committee, which included four interventional cardiologists and four cardiac surgeons. The sponsor funded the study and participated in the selection and management of the sites, the collection of the data, and data monitoring. The first author and members of the executive committee had unrestricted access to the data after the database had been locked and prepared all drafts of the manuscript; they attest to the completeness and accuracy of the reported data and to the adherence of the study to the protocol (available with the full text of this article at NEJM.org). The trial was approved by the institutional review board at each site. Written informed consent was obtained from all patients.

\section{STUDY END POINTS}

The prespecified primary end point of the PARTNER trial was all-cause mortality at 1 year for the pooled cohort. Prespecified secondary end points included cardiovascular mortality, stroke, repeat hospitalization, acute kidney injury, vascular complications, bleeding events, and New York Heart Association (NYHA) functional class. All patients were followed for at least 2 years and had annual clinical visits and echocardiographic evaluations. Crossovers between the two treatment groups were not permitted. A clinical-events committee was 
responsible for adjudicating all end points. Definitions of the end points are identical to those in the original trial and have been reported elsewhere. ${ }^{16,17}$

\section{STATISTICAL ANALYSIS}

For data analyses, the intention-to-treat analysis started at the time of randomization, and the astreated analysis started at the time of induction of anesthesia in the procedure room. All clinical outcomes were primarily analyzed with the use of an intention-to-treat analysis, but the results of as-treated analyses are also presented for comparison. All echocardiographic analyses were performed with the use of the as-treated data. Categorical variables were compared with the use of Fisher's exact test. Continuous variables, presented as means $\pm \mathrm{SD}$, were compared with the use of Student's t-test. Survival curves for time-to-event variables were constructed with the use of Kaplan-Meier estimates based on all available data and were compared with the use of the log-rank test. To study the effect of risk factors on mortality, Cox proportional-hazards regression was performed. For the multivariable analyses, multiple imputations were used to accommodate missing baseline variables. The multivariable models included covariates with a $P$ value of less than 0.20 in univariate analyses. An additional time-dependent covariate analysis was performed to test the association of complications during TAVR or surgical replacement with subsequent mortality. All statistical analyses were performed with the use of SAS software, version 9.2.

\section{RESULTS}

\section{PATIENTS}

In the randomized TAVR group, 244 patients had acceptable vascular access and were treated by means of the transfemoral approach, and the remaining 104 patients were treated by means of the transapical approach. Surgical replacement was performed in 351 patients. Figure 1 in the Supplementary Appendix, available at NEJM.org, shows the study-group assignments and followup. All patients were followed for at least 2 years (median, 727 days; maximum, 1490 days). The overall study population was elderly (mean age, $84.1 \pm 6.6$ years), had severe cardiac symptoms (94.1\% had NYHA class III or IV status), and had frequent coexisting conditions $75.5 \%$ had a his- tory of coronary artery disease, $43.0 \%$ had a history of coronary-artery bypass surgery, $42.4 \%$ had peripheral vascular disease, $43.3 \%$ had pulmonary disease, and $41.3 \%$ had diabetes). The TAVR and surgery groups were generally well matched with regard to baseline characteristics (Table 1 in the Supplementary Appendix), except for a slightly higher incidence of renal dysfunction in the TAVR group (creatinine level $>2$ mg per deciliter [177 $\mu$ mol per liter]: $10.8 \%$, as compared with $6.4 \%$ in the surgery group; $\mathrm{P}=0.04$ ). The mean Society of Thoracic Surgeons predicted risk of death at 30 days was $11.8 \pm 3.4 \%$.

Of the 699 study patients, 42 did not receive the assigned therapy: 4 in the TAVR group and 38 in the surgery group. ${ }^{17}$ The main reasons for nontreatment were withdrawal from the study and the patient's decision not to undergo surgery (28 patients).

\section{MORTALITY AND STROKE}

Outcomes at 30 days and 1 year have been described previously. ${ }^{17}$ For the duration of the trial, there were no significant differences in survival between the TAVR and surgery groups in either the intention-to-treat analysis (hazard ratio with TAVR, $0.90 ; 95 \%$ confidence interval [CI], 0.71 to $1.15 ; \mathrm{P}=0.41$ ) or the as-treated analysis (hazard ratio, $0.98 ; 95 \%$ CI, 0.76 to $1.25 ; \mathrm{P}=0.85$ ) (Fig. 1). Between 1 and 2 years, there were 32 additional deaths in the TAVR group and 25 in the surgery group. At 2 years, there were no significant differences in mortality from any cause between the TAVR group (33.9\%; 95\% CI, 28.9 to 39.0 ) and the surgery group (35.0\%; 95\% CI, 29.8 to 40.2 ; $\mathrm{P}=0.78$ ) (Table 1). Cardiovascular mortality at 2 years was also similar in the TAVR and surgery groups (21.4\% [95\% CI, 16.8 to 26.0 ] and $20.5 \%$ [95\% CI, 15.8 to 25.3], respectively; $\mathrm{P}=0.80$ ). Similarly, in the as-treated analysis, the TAVR and surgery groups did not differ significantly with respect to all-cause mortality $(33.9 \%$ and $32.7 \%$, respectively; $\mathrm{P}=0.75$ ) or cardiovascular mortality ( $20.8 \%$ and $18.5 \%$, respectively; $\mathrm{P}=0.50$ ) (Table 2 in the Supplementary Appendix).

Between 1 and 2 years, eight strokes occurred (four in the TAVR group and four in the surgery group) and three transient ischemic attacks (two in the TAVR group and one in the surgery group). The frequency of all neurologic events (strokes and transient ischemic attacks) at 2 years was higher with TAVR than with surgical replacement (11.2\% 


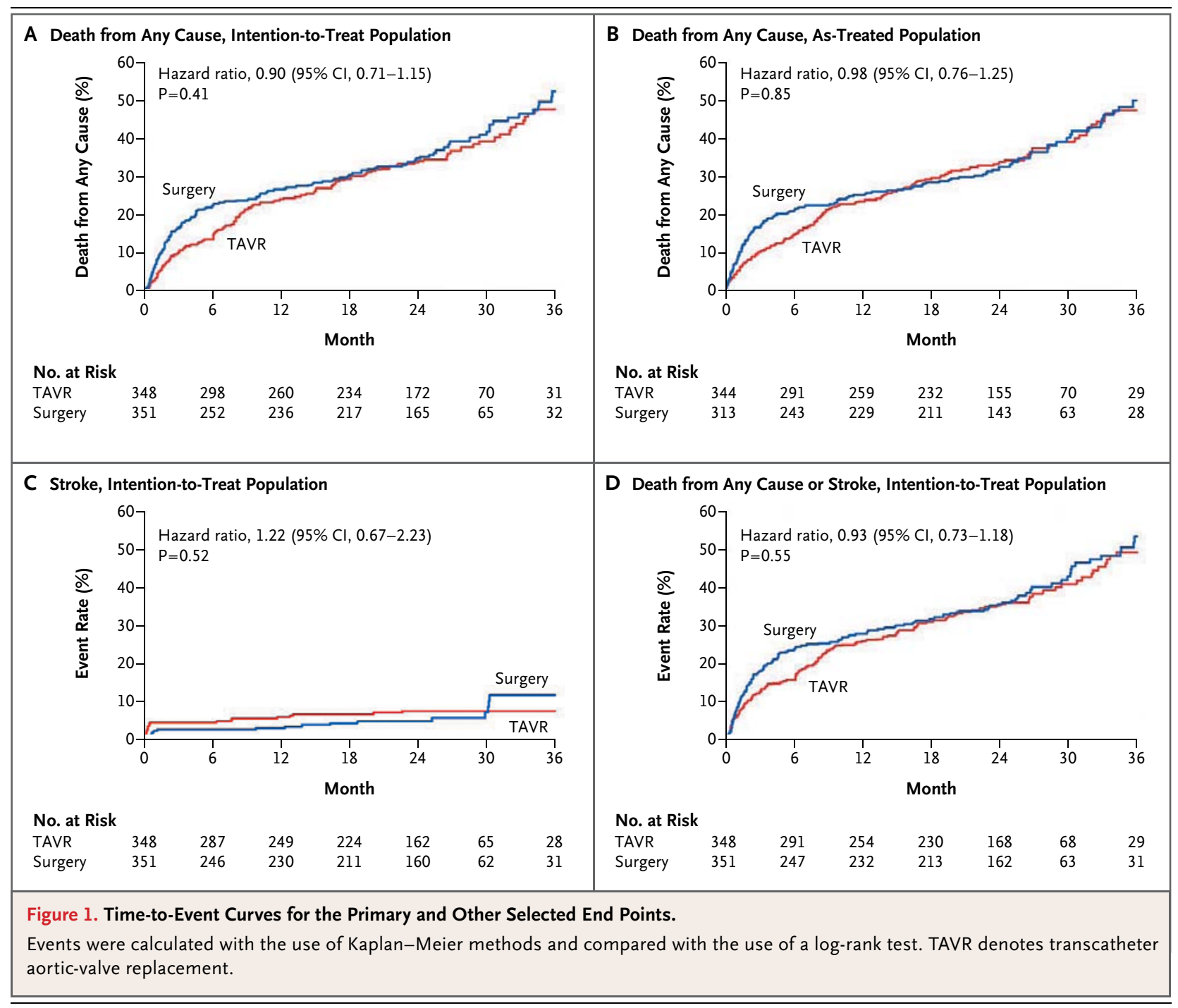

vs. $6.5 \%, \mathrm{P}=0.05)$. However, there was no significant difference in the number of overall strokes between the TAVR and surgery groups (hazard ratio, 1.22; 95\% CI, 0.67 to 2.23; $\mathrm{P}=0.52$ ) (Fig. 1). After the early increased hazard of stroke in the first 30 days associated with TAVR (4.6\% with TAVR vs. $2.4 \%$ with surgical replacement, $\mathrm{P}=0.12$ ), there were 8 additional strokes in the TAVR group and 12 in the surgery group, such that the total number of strokes over the follow-up period (36 months) was 24 in the TAVR group and 20 in the surgery group. The composite of the rate of death from any cause or stroke did not differ significantly between the two treatment groups (hazard ratio, 0.93 ; $95 \% \mathrm{CI}, 0.73$ to $1.18 ; \mathrm{P}=0.55$ ) (Fig. 1); at 2 years, the rate was $37.1 \%$ in the TAVR group and $36.4 \%$ in the surgery group $(\mathrm{P}=0.85)$.

\section{OTHER CLINICAL OUTCOMES}

Other clinical events are summarized in Table 1. Major vascular complications and major bleeding events were frequent procedure-related complications in the TAVR and surgery groups, respectively, but after 1 year, these events were uncommon and did not differ significantly between the groups. No patients were treated with balloon aortic valvuloplasty or repeat TAVR between 1 and 2 years. Endocarditis was rare and occurred at a similar rate in the two groups $(1.5 \%$ in the TAVR group and $1.0 \%$ in the surgery group, $\mathrm{P}=0.61$ ). No patients in either group had structural valve deterioration requiring surgical replacement during follow-up.

At 2 years, there was no significant difference in the rate of repeat hospitalization between the 


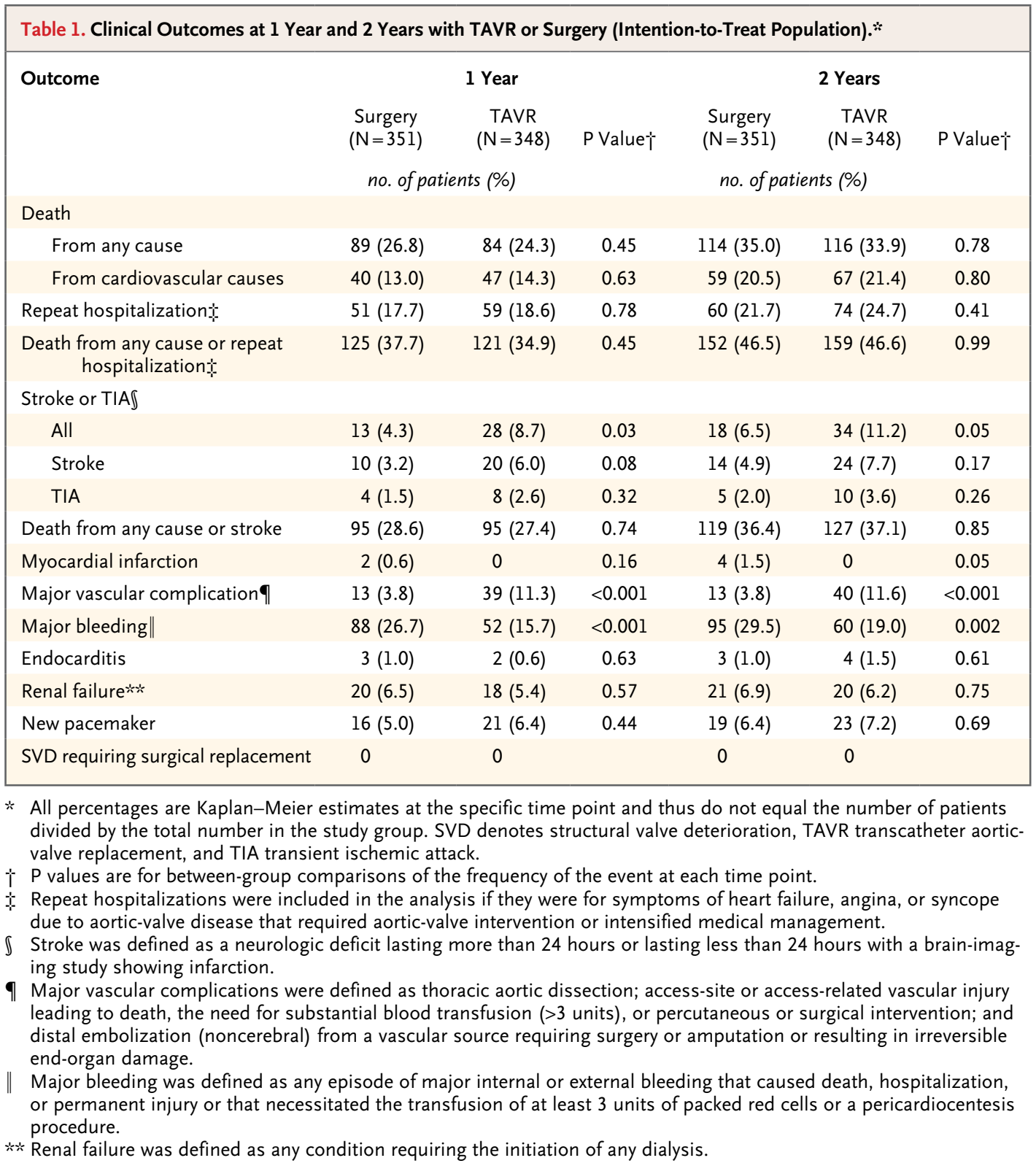

TAVR and surgery groups $(24.7 \%$ and $21.7 \%$, respectively; $\mathrm{P}=0.41$ ). Among survivors at 2 years, the mean NYHA class was similar in the TAVR and surgery groups (1.72 and $1.70, \mathrm{P}=0.87)$, and the majority of patients in both groups had NYHA class I or II status $(83.9 \%$ in the TAVR group and $85.2 \%$ in the surgery group). Clinical outcomes in the subgroups of patients in whom a transfemoral or transapical approach was used are shown in Tables 3 through 6 in the Supplementary Appendix.

\section{PREDICTORS OF MORTALITY}

Predictors of mortality for the overall trial cohort as well as for each of the randomized groups are presented in Table 2. Treatment assignment was not a significant predictor of the risk of death.

The time-dependent effect of treatment complications on subsequent mortality was also evaluated. Strokes greatly increased the hazard of death in both groups (TAVR: hazard ratio, 2.47; 95\% CI, 1.42 to 4.30 ; P<0.001; surgery: hazard ratio, 5.20; 95\% CI, 3.07 to 8.80; $\mathrm{P}<0.001)$. Major 


\begin{tabular}{|c|c|c|}
\hline Variable & $\begin{array}{c}\text { Hazard Ratio } \\
(95 \% \mathrm{CI})\end{array}$ & P Value \\
\hline \multicolumn{3}{|l|}{ Overall } \\
\hline TAVR group & $0.89(0.70-1.13)$ & 0.34 \\
\hline Body-mass index广 & $0.96(0.94-0.98)$ & $<0.001$ \\
\hline Liver disease & $2.24(1.30-4.00)$ & 0.006 \\
\hline Mean gradient per increase of $10 \mathrm{~mm} \mathrm{Hg}$ & $0.89(0.81-0.98)$ & 0.02 \\
\hline STS risk score $\mathbb{Z}$ & $1.04(1.01-1.08)$ & 0.02 \\
\hline Moderate or severe mitral regurgitation at baseline & $1.36(1.02-1.82)$ & 0.04 \\
\hline \multicolumn{3}{|l|}{ TAVR } \\
\hline Body-mass index $\uparrow$ & $0.93(0.90-0.97)$ & $<0.001$ \\
\hline Mean gradient per increase of $10 \mathrm{~mm} \mathrm{Hg}$ & $0.82(0.72-0.94)$ & 0.003 \\
\hline Creatinine level at baseline & $1.06(1.00-1.13)$ & 0.04 \\
\hline Prior vascular surgery or stent & $1.85(1.01-3.39)$ & 0.05 \\
\hline \multicolumn{3}{|l|}{ Surgery } \\
\hline CABG & $0.57(0.40-0.82)$ & 0.002 \\
\hline STS risk score $\mathbb{Z}$ & $1.07(1.02-1.12)$ & 0.004 \\
\hline Liver disease & $2.59(1.16-5.43)$ & 0.02 \\
\hline Moderate or severe mitral regurgitation at baseline & $1.77(1.17-2.68)$ & 0.006 \\
\hline \multicolumn{3}{|c|}{$\begin{array}{l}\text { Unless otherwise indicated, the hazard ratio reflects the presence or absence of the variable. CABG denotes coronary- } \\
\text { artery bypass grafting. } \\
\text { For body-mass index (the weight in kilograms divided by the square of the height in meters), the hazard ratio reflects } \\
\text { an increase of } 1 \text {. } \\
\text { Liver disease indicates a history of any liver condition. } \\
\text { The Society of Thoracic Surgeons (STS) risk score predicts the } 30 \text {-day risk of death (on a scale of } 0 \% \text { to } 100 \% \text {, with } \\
\text { higher scores indicating higher predicted risk). The hazard ratio reflects an increase of } 1 \% \text {. } \\
\text { For creatinine level at baseline, the hazard ratio reflects an increase of } 1 \mathrm{mg} \text { per deciliter. }\end{array}$} \\
\hline
\end{tabular}

bleeding also increased the hazard of death in both groups (TAVR: hazard ratio, 2.11; 95\% CI, 1.41 to 3.17; $\mathrm{P}<0.001$; surgery: hazard ratio, 2.94; $95 \% \mathrm{CI}, 2.08$ to 4.15 ; $\mathrm{P}<0.001)$. Major vascular complications affected survival only in the TAVR group (hazard ratio, 1.71; 95\% CI, 1.07 to 2.73; $\mathrm{P}=0.02)$.

\section{ECHOCARDIOGRAPHIC FINDINGS}

The early hemodynamic improvements that were seen with both surgical replacement and TAVR were maintained at 2 years, with no significant changes in valve areas or mean gradients (Fig. 2). Moderate or severe paravalvular aortic regurgitation was more common after TAVR than after surgical replacement at both 1 and 2 years $(7.0 \%$ vs. $1.9 \%$ at 1 year, and $6.9 \%$ vs. $0.9 \%$ at 2 years; $\mathrm{P}<0.001$ for both comparisons). Among the 143 patients who underwent echocardiographic eval- uation 2 years after TAVR, paravalvular aortic regurgitation remained unchanged in $46.2 \%$ of patients, was improved in $31.5 \%$, and was worse in 22.4\% (Table 7 in the Supplementary Appendix). The presence of paravalvular or total aortic regurgitation (mild, moderate, or severe vs. none or trace) after TAVR was associated with increased late mortality (hazard ratio, 2.11; 95\% CI, 1.43 to 3.10; $\mathrm{P}<0.001$ ) (Fig. 3). The effect of aortic regurgitation on mortality was proportional to the severity of the regurgitation (Fig. 3), but even mild aortic regurgitation was associated with an increased rate of late deaths.

\section{DISCUSSION}

The salient findings from this 2-year analysis of the randomized PARTNER trial are as follows: mortality after TAVR remained similar to that 


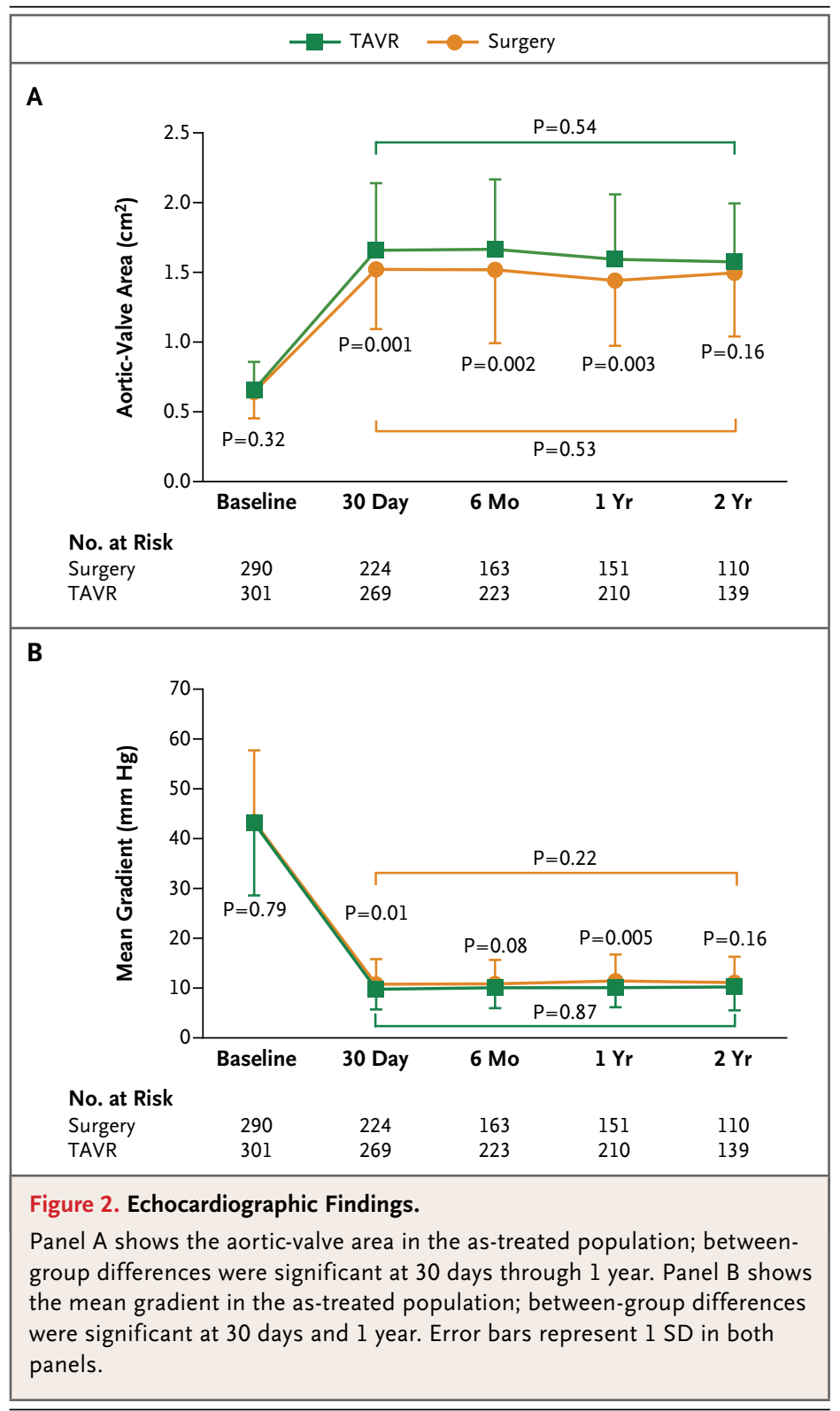

after surgical replacement, stroke frequency was similar in the surgery and TAVR groups after 30 days, periprocedural complications (strokes, major bleeding, and major vascular events) affected mortality after TAVR or surgical replacement; aortic regurgitation (even mild) after TAVR was associated with increased long-term mortality, and valve performance in the TAVR group was maintained during follow-up and was similar to that in the surgery group.

Early (30-day) mortality after TAVR has decreased to approximately $5 \%$ in several recent studies, probably because of a combination of improvements in patient selection, procedural tech- niques, and device technologies. ${ }^{12,14,16-18}$ However, 1- and 2-year mortality rates have remained above $20 \%$ and $30 \%$, respectively, ${ }^{11,15,19,20}$ raising a concern that TAVR may be associated with important late complications. The results from the PARTNER trial reveal similarly high mortality at 2 years with TAVR and with surgical replacement, indicating that coexisting conditions play a role in late mortality. The multivariable analysis from the combined TAVR and surgery groups affirms the importance of coexisting conditions, because the STS risk score was a significant predictor of mortality at 2 years. Although the STS score was designed to predict 30-day mortality after surgical replacement, ${ }^{21}$ many of the baseline characteristics of the patients are also likely contributors to late mortality.

The 30-day and 1-year PARTNER results raised concern that TAVR was responsible for increased early and, possibly, late strokes. ${ }^{16,17}$ The differences in stroke frequencies appeared in the first few days or weeks after TAVR, presumably owing to increased liberation of atherothrombotic debris (from the valve or aorta), causing embolic ischemic strokes. After this initial period, there is no evidence of higher stroke rates in either group, suggesting that the constant hazard of late strokes in these elderly high-risk patients is unrelated to the mode of valve-replacement therapy. The preferred anticoagulation regimen (early and late) for patients after TAVR has not been determined. ${ }^{22}$ Early experiences with new cerebral filters ${ }^{23}$ suggest the frequent appearance of captured atherothrombotic material after TAVR, but careful clinical studies with these new devices are just beginning.

The current study shows stable gradients and unchanged valve areas with the SAPIEN valve at 2 years. Nevertheless, structural valve deterioration is well known with surgical bioprostheses, and definitive assessments of valve durability will require much longer follow-up..$^{24-26}$

A design limitation of transcatheter aortic valves has been paravalvular regurgitation, which results from incomplete circumferential apposition of the prosthesis with the annulus. Several reports have indicated a relation between paravalvular regurgitation and mortality, but the certainty of these findings has been limited by the lack of standardization of methods to assess aortic regurgitation. ${ }^{11,12,27,28}$ In our study, semiquantitative measures of aortic-regurgitation severity were evaluated in an echocardiography core labo- 


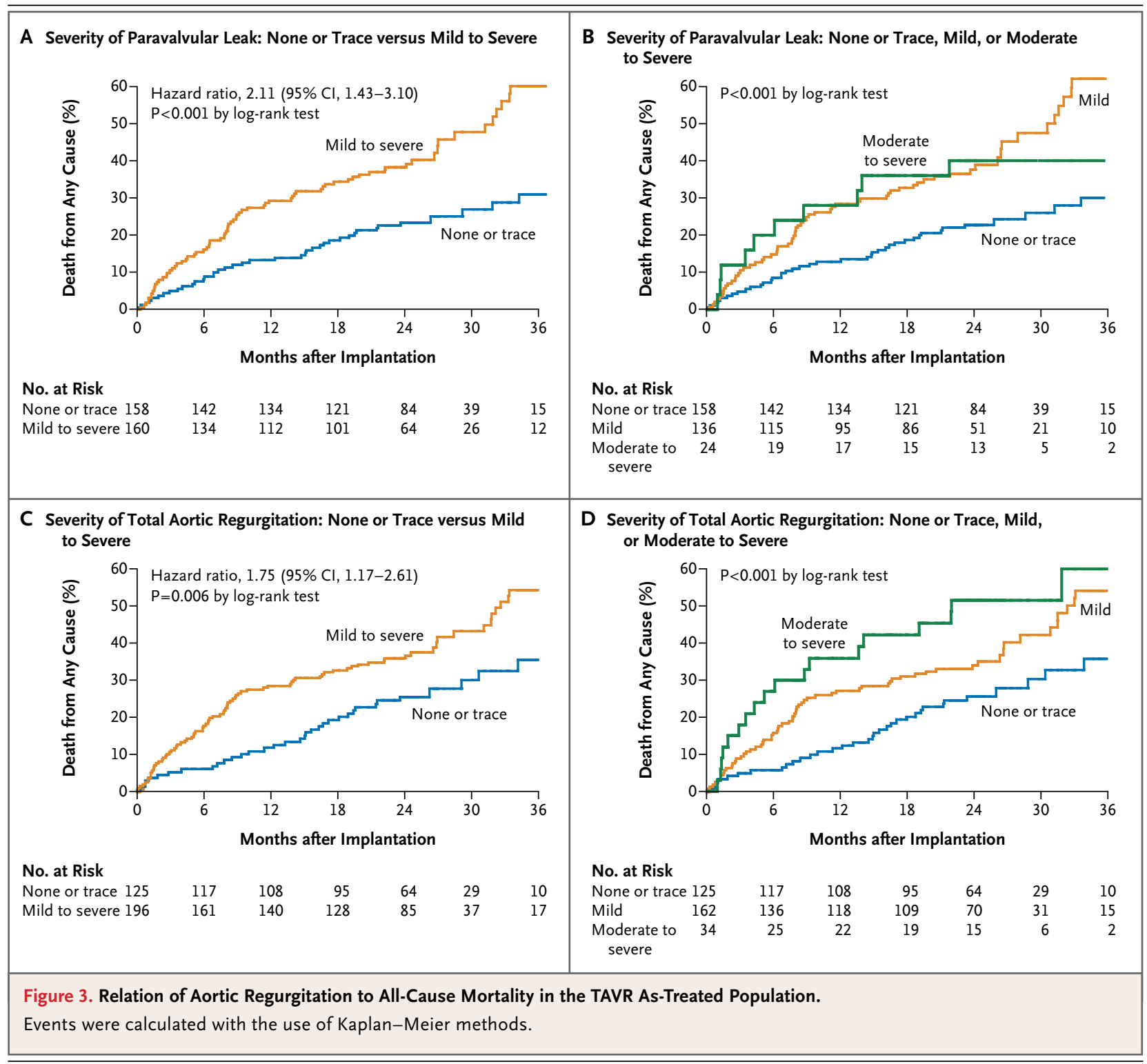

ratory; these assessments indicated a low frequency of moderate or severe paravalvular aortic regurgitation (approximately 10\%). Paravalvular aortic regurgitation remained stable without significant worsening during follow-up. Nevertheless, even mild paravalvular (or total) aortic regurgitation (occurring in approximately $40 \%$ of patients) was associated with increased late mortality (Fig. 3). Conversely, the absence of paravalvular aortic regurgitation or only trace regurgitation was associated with lower mortality in the TAVR group.

These findings provide an important target for improving outcomes after TAVR in the future. The factors that underlie paravalvular aortic re- gurgitation include the ratio of the transcathetervalve size to the size of the annulus, the position of the prosthetic valve, and the pattern of calcification in the native valve. ${ }^{29-32}$ In the PARTNER trial, the valve cover index, ${ }^{32}$ defined as $100 \times$ [(valve prosthesis diameter - annulus diameter) $\div$ valve prosthesis diameter], was lower in patients with paravalvular aortic regurgitation, implicating systematic valve undersizing as an important causative factor. Recently, the routine use of threedimensional imaging techniques has improved annulus sizing, resulting in better selection of properly sized valves. ${ }^{33-37}$ In addition, the selective use of post-TAVR dilation of the transcatheter valve with slightly larger balloons may reduce im- 
mediate paravalvular aortic regurgitation during TAVR, but the risks of aortic rupture, increased central aortic regurgitation, and increased embolic events must be considered. Future generations of TAVR devices with improved subannular fixation designs or external space-filling materials may also reduce incomplete apposition.

Several study limitations should be acknowledged. First, patients frequently declined surgery after random assignment to surgical replacement, resulting in a higher proportion of patients in the surgery group who did not receive the assigned treatment. Nonetheless, there were no significant differences in clinical outcomes between the intention-to-treat cohort and the as-treated cohort. Second, stroke assessments were limited, since neurologic assessments were not mandated, modified Rankin scores were not used to determine clinical disability, and documentation of atrial fibrillation episodes and anticoagulation regimens was not complete. Third, the small number of patients in whom the transapical approach was used and the differences in baseline characteristics make a comparison of the transfemoral and transapical subgroups unreliable. Finally, this study represented the initial experience with TAVR at most of the sites, with the use of a first-generation device. Multiple reports suggest that subsequent device generations and increased operator experience with TAVR may improve outcomes. ${ }^{18,38-40}$

In conclusion, this 2-year follow-up of patients in the PARTNER trial supports the use of TAVR as an alternative to surgery in selected high-risk patients with aortic stenosis. The two treatments were similar with respect to mortality, reduction in cardiac symptoms, and improved valve hemodynamics. The early increase in the risk of stroke with TAVR was attenuated over time. A new, important observation was the association of para- valvular regurgitation after TAVR with late mortality. Work now should be directed toward reducing paravalvular aortic regurgitation with improved device designs, techniques for more precise valve sizing and positioning, and judicious use of post-TAVR dilation.

Ms. Akin reports being an employee of Edwards Lifesciences; Dr. Anderson, receiving consulting fees and fees for manuscript preparation and owning stock in Edwards Lifesciences; Dr. Dewey, receiving consulting fees and lecture fees from Edwards Lifesciences; Dr. Douglas, being a board member of Translational Research in Oncology and CardioDx and receiving grant funding from the Agency for Healthcare Research and Quality, Atritech, Ikaria, and Viacor on behalf of her institution; Dr. Fischbein, receiving consulting fees from Edwards Lifesciences and grant funding from the National Marfan Foundation on behalf of his institution; Dr. Fontana, receiving consulting fees and lecture fees from Edwards Lifesciences, receiving consulting fees from and owning stock or stock options in Entourage Medical Technologies, receiving consulting fees and lecture fees from Medtronic, receiving consulting fees and lecture fees from Sorin, and receiving consulting fees and lecture fees from St. Jude Medical; Dr. Kodali, being a medical advisory board member of Paieon Medical, receiving consulting fees from Edwards Lifesciences, Medtronic, and St. Jude Medical, and owning stock options in Thubrikar Aortic Valve; Dr. Makkar, receiving consulting fees from and owning stock or stock options in Entourage Medical Technologies, receiving consulting fees from $\mathrm{Ab}$ bott, Abiomed, Cordis, and Medtronic, providing expert testimony for the law office of Pivo, Halbreich, Martin, Wilson \& Amo, receiving grant funding from Edwards Lifesciences on behalf of his institution and reimbursement for travel expenses from Edwards Lifesciences on behalf of his institution, receiving lecture fees from Eli Lilly, and receiving reimbursement for travel expenses from St. Jude Medical on behalf of his institution and compensation from St. Jude Medical for being the national principal investigator of its valve trial; Dr. Malaisrie, receiving consulting fees from Baxter, Edwards Lifesciences, and Medtronic; Dr. Teirstein, receiving grant funding and payment for manuscript preparation from Edwards Lifesciences and Medtronic on behalf of his institution; Dr. Thourani, being an advisory board member of Edwards Lifesciences; Dr. Webb, receiving consulting fees and lecture fees from Edwards Lifesciences on behalf of himself and grant funding from Edwards Lifesciences on behalf of his institution; and Dr. Williams, receiving consulting fees from Edwards Lifesciences. No other potential conflicts of interest were reported. Disclosure forms provided by the authors are available with the full text of this article at NEJM.org.

We thank Ajay Kirtane, M.D., and Maria Alu (Columbia University Medical Center) and Phil Hall (Edwards Lifesciences) for their contributions to this manuscript.
REFERENCES

1. Bonow RO, Carabello BA, Chatterjee $\mathrm{K}$, et al. 2008 Focused update incorporated into the ACC/AHA 2006 guidelines for the management of patients with valvular heart disease: a report of the American College of Cardiology/American Heart Association Task Force on Practice Guidelines (Writing Committee to Revise the 1998 Guidelines for the Management of Patients with Valvular Heart Disease): endorsed by the Society of Cardiovascular Anesthesiologists, Society for Cardiovascular Angiography and Interventions, and
Society of Thoracic Surgeons. Circulation 2008;118(15):e523-e661.

2. Bach DS, Siao D, Girard SE, Duvernoy C, McCallister BD Jr, Gualano SK. Evaluation of patients with severe symptomatic aortic stenosis who do not undergo aortic valve replacement: the potential role of subjectively overestimated operative risk. Circ Cardiovasc Qual Outcomes 2009;2: 533-9.

3. Iung B, Baron G, Butchart EG, et al A prospective survey of patients with valvular heart disease in Europe: the Euro
Heart Survey on Valvular Heart Disease. Eur Heart J 2003;24:1231-43.

4. Varadarajan P, Kapoor N, Bansal RC, Pai RG. Clinical profile and natural history of 453 nonsurgically managed patients with severe aortic stenosis. Ann Thorac Surg 2006;82:2111-5.

5. Pellikka PA, Sarano ME, Nishimura RA, et al. Outcome of 622 adults with asymptomatic, hemodynamically significant aortic stenosis during prolonged follow-up. Circulation 2005;111:3290-5.

6. Cribier A, Eltchaninoff $\mathrm{H}$, Bash A, et 
al. Percutaneous transcatheter implantation of an aortic valve prosthesis for calcific aortic stenosis: first human case description. Circulation 2002;106:3006-8.

7. Ye J, Cheung A, Lichtenstein SV, et al. Transapical transcatheter aortic valve implantation: 1-year outcome in 26 patients. J Thorac Cardiovasc Surg 2009;137:167-73.

8. Webb JG, Pasupati S, Humphries K, et al. Percutaneous transarterial aortic valve replacement in selected high-risk patient with aortic stenosis. Circulation 2007;116: 755-63.

9. Walther T, Kasimir MT, Doss M, et al. One-year interim follow-up results of the TRAVERCE trial: the initial feasibility study for trans-apical aortic-valve implantation. Eur J Cardiothorac Surg 2010;39:532-7.

10. Piazza N, Grube E, Gerckens U, et al Procedural and 30-day outcomes following transcatheter aortic valve implantation using the third generation (18F) CoreValve Revalving system - results from the Multicenter, Expanded Evaluation Registry 1 year after being CE mark approved, on behalf of all actively par ticipating centers. Circulation 2008;118: Suppl 2:S807. abstract.

11. Moat NE, Ludman P, de Belder MA, et al. Long-term outcomes after transcathe ter aortic valve implantation in high-risk patients with severe aortic stenosis: the U.K. TAVI (United Kingdom Transcatheter Aortic Valve Implantation) Registry. J Am Coll Cardiol 2011;58:2130-8.

12. Tamburino C, Capodanno D, Ramon do $\mathrm{A}$, et al. Incidence and predictors of early and late mortality after transcatheter aortic valve implantation in 663 pa tients with severe aortic stenosis. Circulation 2011;123:299-308.

13. Gotzmann M, Bojara W, Lindstaed $\mathrm{M}$, et al. One-year results of transcatheter aortic valve implantation in severe symptomatic aortic valve stenosis. Am J Cardio 2011;107:1687-92.

14. Thomas M, Schymik G, Walther T, et al. Thirty-day results of the SAPIEN aortic Bio prosthesis European Outcome (SOURCE) Registry: a European registry of transcatheter aortic valve implantation using the Edwards SAPIEN valve. Circulation 2010;122:62-9.

15. Gurvitch R, Wood DA, Tay EL, et al. Transcatheter aortic valve implantation: durability of clinical and hemodynamic outcomes beyond 3 years in a large patient cohort. Circulation 2010;122:1319-27.

16. Leon MB, Smith CR, Mack M, et al. Transcatheter aortic-valve implantation for aortic stenosis in patients who cannot undergo surgery. N Engl J Med 2010; 363:1597-607.

17. Smith CR, Leon MB, Mack MJ, et al.
Transcatheter versus surgical aortic-valve replacement in high-risk patients. $\mathrm{N}$ Engl J Med 2011;364:2187-98.

18. Gurvitch R, Tay EL, Wijesinghe N, et al. Transcatheter aortic valve implantation: lessons from the learning curve of the first 270 high-risk patients. Catheter Cardiovasc Interv 2011;78:977-84.

19. Bleiziffer S, Mazzitelli D, Opitz A, et al. Beyond the short-term: clinical outcome and valve performance 2 years after transcatheter aortic valve implantation in 227 patients. J Thorac Cardiovasc Surg 2012; 143:310-7.

20. Ussia GP, Barbanti M, Petronio AS, et al. Transcatheter aortic valve implantation: 3-year outcomes of self-expanding CoreValve prosthesis. Eur Heart J 2012 January 12 (Epub ahead of print).

21. Shroyer AL, Coombs LP, Peterson ED, et al. The Society of Thoracic Surgeons: 30-day operative mortality and morbidity risk models. Ann Thorac Surg 2003;75: 1856-65.

22. Ussia GP, Scarabelli $M$, Mulè $M$, et al. Dual antiplatelet therapy versus aspirin alone in patients undergoing transcatheter aortic valve implantation. Am J Cardiol 2011;108:1772-6.

23. Nietlispach F, Wijesinghe N, Gurvitch $\mathrm{R}$, et al. An embolic deflection device for aortic valve interventions. JACC Cardiovasc Interv 2010;3:1133-8.

24. Heras M, Chesebro JH, Fuster V, et al. High risk of thromboemboli early after bioprosthetic cardiac valve replacement. J Am Coll Cardiol 1995;25:1111-9.

25. Schoen FJ, Levy RJ. Calcification of tissue heart valve substitutes: progress toward understanding and prevention. Ann Thorac Surg 2005;79:1072-80.

26. Ruel M, Kulik A, Lam BK, et al. Longterm outcomes of valve replacement with modern prostheses in young adults. Eur J Cardiothorac Surg 2005;27:425-33.

27. Abdel-Wahab M, Zahn R, Horack $M$, et al. Aortic regurgitation after transcatheter aortic valve implantation: incidence and early outcome: results from the German transcatheter aortic valve interventions registry. Heart 2011;97:899-906.

28. Gotzmann M, Pljakic A, Bojara W, et al. Transcatheter aortic valve implantation in patients with severe symptomatic aortic valve stenosis - predictors of mortality and poor treatment response. Am Heart J 2011;162(2):238.e1-245.e1.

29. Koos R, Mahnken AH, Dohmen G, et al. Association of aortic valve calcification severity with the degree of aortic regurgitation after transcatheter aortic valve implantation. Int J Cardiol 2010;150:142-5. 30. Haensig M, Lehmkuhl L, Rastan AJ, et al. Aortic valve calcium scoring is a pre- dictor of significant paravalvular aortic insufficiency in transapical-aortic valve implantation. Eur J Cardiothorac Surg 2012 January 12 (Epub ahead of print).

31. Colli A, D’Amico R, Kempfert J, Borger MA, Mohr FW, Walther T. Transesophageal echocardiographic scoring for transcatheter aortic valve implantation: impact of aortic cusp calcification on postoperative aortic regurgitation. J Thorac Cardiovasc Surg 2011;142:1229-35.

32. Detaint D, Lepage L, Himbert D, et al. Determinants of significant paravalvular regurgitation after transcatheter aortic valve implantation: impact of device and annulus discongruence. JACC Cardiovasc Interv 2009;2:821-7.

33. Leipsic J, Gurvitch R, Labounty TM, et al. Multidetector computed tomography in transcatheter aortic valve implantation. JACC Cardiovasc Imaging 2011;4:416-29.

34. Koos R, Altiok E, Mahnken AH, et al. Evaluation of aortic root for definition of prosthesis size by magnetic resonance imaging and cardiac computed tomography: implications for transcatheter aortic valve implantation. Int J Cardiol 2011 February 9 (Epub ahead of print).

35. Tzikas A, Schultz CJ, Piazza N, et al. Assessment of the aortic annulus by multislice computed tomography, contrast aortography, and trans-thoracic echocardiography in patients referred for transcatheter aortic valve implantation. Catheter Cardiovasc Interv 2011;77:868-75.

36. Jabbour A, Ismail TF, Moat $\mathrm{N}$, et al. Multimodality imaging in transcatheter aortic valve implantation and post-procedural aortic regurgitation: comparison among cardiovascular magnetic resonance, cardiac computed tomography, and echocardiography. J Am Coll Cardiol 2011;58:2165-73.

37. Tops LF, Wood DA, Delgado V, et al. Noninvasive evaluation of the aortic root with multislice computed tomography implications for transcatheter aortic valve replacement. JACC Cardiovasc Imaging 2008;1:321-30.

38. Alli OO, Booker JD, Lennon RJ, Greason KL, Rihal CS, Holmes DR Jr. Transcatheter aortic valve implantation: assessing the learning curve. JACC Cardiovasc Interv 2012;5:72-9.

39. Kempfert J, Rastan A, Holzhey D, et al. Transapical aortic valve implantation: analysis of risk factors and learning experience in 299 patients. Circulation 2011; 124:Suppl:S124-S129.

40. Webb JG, Altwegg L, Boone RH, et al. Transcatheter aortic valve implantation: impact on clinical and valve-related outcomes. Circulation 2009;119:3009-16.

Copyright (c) 2012 Massachusetts Medical Society. 